\title{
Theoretical Interpretation of Residence-Time Distribution Measurements in Industrial Processes
}

\author{
J.-P. Leclerc ${ }^{1}$, S. Claudel ${ }^{1}$, H.-G. Lintz ${ }^{1}, 0$. Potier ${ }^{1}$ and B. Antoine ${ }^{2}$ \\ 1 PRO G EPI, Laboratoire des sciences du génie chimique-CN RS-EN SIC, 1, rue G randville, BP 451, 54001 N ancy Cedex - France \\ 2 Laboratoire d'énergétique et de mécanique théorique et appliquée-C N RS-EN SEM, \\ 2, avenue de la Forêt-de-Haye, 54516 Vandœuvre-les-N ancy Cedex - France \\ e-mail: propegi@ensic.u-nancy.fr
}

\begin{abstract}
Résumé - Distribution des temps de séjour dans les procédés industriels : interprétation théorique — Le concept de Distribution des Temps de Séjour (DTS) a été introduit par Danckwerts en 1953 afin de caractériser l'écoulement dans les réacteurs. Il a été décrit de nombreuses fois et appliqué à des cas divers. Bien que les récents développements des codes de calcul de mécanique des fluides doivent permettre de mieux comprendre le fonctionnement des procédés industriels, les applications de ces codes restent difficiles pour des procédés complexes. La méthode des distributions des temps de séjour reste alors la seule voie possible pour obtenir des informations sur l'hydrodynamique et améliorer ces procédés.
\end{abstract}

Les modèles représentatifs des expériences de traçage se limitent souvent à des réacteurs simples, comme les cascades de réacteurs parfaitement agités en série ou le réacteur piston à dispersion axiale, et l'information ainsi déduite peut se révéler très insuffisante. La création de modèles hydrodynamiques obtenus par la création de réseaux complexes de réacteurs élémentaires peut permettre d'obtenir des informations plus précises sur un procédé. Cependant, cette approche induit deux problèmes de fond : premièrement la résolution rapide d'un système d'équations quels que soient le réseau et les réacteurs choisis, deuxièmement la difficulté à obtenir un modèle réaliste et représentatif de la physique du procédé.

En fait, les réseaux complexes contiennent tellement de paramètres que deux modèles très différents peuvent répondre de la même façon à un signal d'entrée quelconque, ou qu'un même modèle peut donner des réponses similaires avec des jeux de paramètres différents. En tenant compte de ces difficultés, un logiciel a été développé afin de calculer facilement la réponse de réseaux complexes à un signal d'entrée quelconque. Ce logiciel permet aussi d'étudier les systèmes à entrées et/ou sorties multiples et d'optimiser les paramètres des modèles correspondants, et peut également être utilisé pour déterminer les paramètres qui permettront d'obtenir des réponses identiques avec deux modèles différents. L'analyse physique de ces paramètres permet ensuite de déterminer le modèle le plus réaliste. Enfin, les mesures expérimentales locales peuvent être interprétées grâce à la possibilité d'obtenir les réponses du modèle en tout point du réseau.

Une procédure générale d'optimisation des débits, dans le cas de procédés industriels comportant des recirculations pour lesquelles les débits sont indéterminés, a aussi été développée. Des perspectives de développement incluant notamment les DTS en régime transitoire et la génération automatique de modèles d'écoulement sont aussi présentées. Elles sont illustrées par des exemples expérimentaux et des résultats tirés de la littérature. Finalement, des perspectives et de nouveaux concepts possibles sont présentés.

Mots-clés : distribution des temps de séjour, procédés industriels complexes, régime transitoire, modélisation. 


\begin{abstract}
Theoretical Interpretation of Residence-Time Distribution Measurements in Industrial Processes - The Residence-Time Distribution (RTD) is a chemical engineering concept introduced by Danckwerts in 1953. It has been described in a multitude of scientific papers and applied for various industrial processes. The development of Computer Fluid Dynamics will improve the comprehension and optimisation of such processes. However, this approach remains difficult in case of complex industrial processes. Therefore, the extension of the RTD concept is an alternative way to obtain hydrodynamic data and help for improvement of the processes.

Actually, the models derived from tracer experiments are often restricted to the use of simple elementary reactors such as perfect mixing cells in series or plug flow with axial dispersion. The resulting information is often not sufficient for the understanding of complex processes. Better understanding may be obtained by the creation of complex networks of interconnected elementary reactors. However, that can lead to two problems to be solved: the first one is the possibility to realise an easy simulation of any complex network, the second one is to create realistic models on a sound physical basis.

Indeed, complex models contain so many parameters that two different models may give the same result or the same model may give an identical result with different sets of parameters. A software package has been developed to simulate the response to an input of any complex network of elementary reactors properly interconnected. Processes with multiple inlets or outlets can be modelled by convolution and optimisation procedures. The software may equally be used to determine the parameters of different models giving the same response, and the subsequent examination of the physical soundness of these parameters leads to the choice of a realistic model. In addition, local measurements may be validated through the possibility to simulate the local response within the model and to optimise the corresponding parameters.
\end{abstract}

Also, a general procedure has been developed to optimise the different flow rates of models in complex industrial processes with many undetermined recirculation flow rates. Future developments including RTD under transient state and automatic generation of flow models are also presented. They are illustrated through experiments and literature analysis. Finally, different perspectives of recent concepts are suggested.

Keywords: residence-time distribution, complex industrial processes, transient state, modelling.

\section{NOTATIONS}

d divisor of $N$

$C$ outlet concentration of tracer at current time

$C_{0} \quad$ initial concentration of tracer

$E_{\theta} \quad$ dimensionless function of Residence-Time Distribution

$E_{\theta^{\prime}} \quad$ dimensionless function of Residence-Time Distribution ( $Q_{S}$ variable)

$E_{\theta "} \quad$ dimensionless function of Residence-Time Distribution ( $Q_{S}$ et $V$ variable)

$G \quad$ transfer function

$M \quad$ quantity of tracer injected

$N \quad$ number of reactors or number of intervals

Pe Peclet number

$Q \quad$ volumetric flow rate of fluid

$Q_{E} \quad$ volumetric inlet flow rate

$Q_{S} \quad$ volumetric outlet flow rate

$t_{0} \quad$ initial time

$t$ current time

$T$ period of signal

[G] matrix complex of the transfer of a size equal to the number of the nodes
[C] matrix column of the concentrations found by the nodes

[K] matrix column constant that characterises the impulse of the incoming flow made by the injection node chosen

$\hat{x}(t)$ periodical signal

$X(v)$ Fourier transform of signal $\hat{x}(t)$

\section{Greek Letters}

$\alpha \quad$ back flow rate

$\tau \quad$ space time $V / Q$

$\mathrm{v}_{0} \quad$ frequency of signal $\hat{x}(t)$

$\checkmark \quad$ frequency

$\theta \quad$ dimensionless time

$\theta^{\prime} \quad$ dimensionless time, $E V / Q_{S}\left(Q_{S}\right.$ variable $)$

$\theta^{\prime \prime} \quad$ dimensionless time, $E V / Q_{S}\left(Q_{S}\right.$ et $V$ variable $)$

\section{INTRODUCTION}

The Residence-Time Distribution (RTD) is a chemical engineering concept introduced by Danckwerts in 1953. It has been described in a multitude of scientific papers and 
applied for various industrial processes. The development of Computer Fluid Dynamics will improve the understanding and optimisation of processes. This method has been successfully tested for simple flow patterns like sedimentation tanks in waste water treatment (Matko et al., 1996). However, for complex systems, this approach remains difficult. Therefore, the extension of the RTD concept is a way to obtain hydrodynamic data and to permit the improvement of processes. The models derived from tracer experiments are often limited to simple elementary reactors such as perfect mixing cells in series (Lin et al., 1999), plug flow with axial dispersion (van Hasselt et al., 1999), mixing cells in series exchanging with a dead zone (Leclerc et al., 1996) or simple compartment models (Levenspiel, 1999). The obtained results are not sufficient to understand complex processes. The creation of a complex network of interconnected elementary reactors makes possible to get better results more easily than with Computer Fluid Dynamics. A general software has been developed to help applications of this concept. A procedure for the optimisation of flow rates is also presented in order to simulate complex processes with recirculation.

The main limiting assumption of the application of the concept is that the studied process runs under steady state during the tracer experiment. Unfortunately, this assumption is too restrictive for many processes such evaporators (Calu and Lameloise, 1986) or waste water treatment plants. The first publication relative to the use of the systemic approach in transient state is due to Nauman (1969) who developed it in case of a perfect mixing cell. Niemi Antti (1977) has extended the work to different models. More recently, Niemi Antti et al. (1998) and Fernandez-Sempere, Font-Montesinos and Espejo-Alcaraz (1995) have experimentally applied this concept. The recent discussion between the authors (Niemi Antti, 1997; Fernandez-Sempere, 1997) shows that it remains still questionable.

\section{SIMULATION OF COMPLEX COMPARTMENT MODELS}

The creation of complex networks of interconnected elementary reactors can lead to two problems to be solved:

- the first one is the possibility to realise an easy simulation of any complex network;

- the second one is to create realistic models on a sound physical basis.

Indeed, complex models contain so many parameters that two different models may give the same result or the same model may give an identical result with different sets of parameters. A software package has been developed to simulate the response to an input of any complex network of elementary reactors properly interconnected. Processes with multiple inlets or outlets can be modelled by convolution and optimisation procedures. The software may also be used to determine the parameters of the different models giving the same response, and the subsequent test of the physical soundness of these parameters leads to the choice of a realistic model. In addition, local measurements may be validated through the possibility to simulate the local response within the model and to optimise the corresponding parameters.

Figure 1 shows a typical complex network of elementary reactors involving plug flow reactors, perfect mixing cells in series and perfect mixing cells in series exchanging with a dead zone. The network is described in terms of so-called branches and nodes. The software can simulate the response to an input of any complex network (Leclerc et al., 1995). Eight different elementary reactors may be chosen (Table 1). The transfer function and the characteristics of these reactors have been already described by many authors (e.g. Levenspiel, 1999; Villermaux, 1995). These models involve a large number of parameters, which should be properly determined to avoid the representation of the experimental

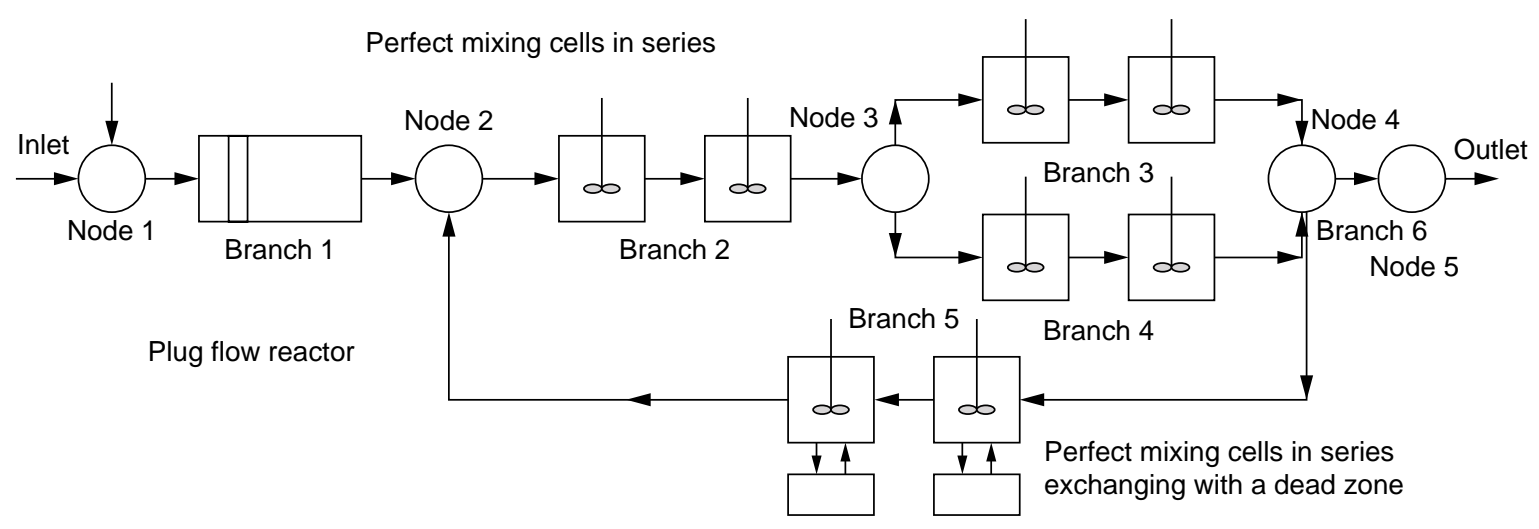

Figure 1

Typical complex network of elementary reactors. 
results by a model without any physical meaning. The analysis of the RTD curve and of the physics of the process itself coupled with coloured tracers (when it is possible) is generally sufficient to overcome the problem. The local tracer experiments inside the studied reactor can be used to validate the model through optimisation at the different nodes. The recent developments in radiotracer technology (Blet et al., 1998) and the use of novel tracers (Muhr, Leclerc and David, 1999) permit to obtain much more information in this regard.

\section{TABLE 1}

Parameters of each elementary reactor

\begin{tabular}{l|l}
\hline \multicolumn{1}{c|}{ Elementary reactor } & \multicolumn{1}{c}{ Parameters } \\
\hline Perfect mixing cell & Mean residence time: $\tau$ \\
\hline Plug flow reactor & Mean residence time: $\tau$ \\
\hline Perfect mixing cells in series & $\begin{array}{l}\text { Mean residence time: } \tau \\
\text { Number of mixing cells: } N\end{array}$ \\
\hline Perfect mixing cells in series & $\begin{array}{l}\text { Mean residence time: } \tau \\
\text { exchanging with a dead zone }\end{array}$ \\
& $\begin{array}{l}\text { Number of mixing cells : } N \\
\text { Exchange time constant: } t_{m} \\
\text { Volume ratio: } K\end{array}$ \\
\hline $\begin{array}{l}\text { Perfect mixing cells in series with } \\
\text { backmixing }\end{array}$ & $\begin{array}{l}\text { Mean residence time: } \tau \\
\text { Number of mixing cells: } N \\
\text { Back flow rate ratio: } \alpha\end{array}$ \\
\hline $\begin{array}{l}\text { Plug flow reactor with axial dispersion } \\
\text { closed to the diffusion }\end{array}$ & $\begin{array}{l}\text { Mean residence time: } \tau \\
\text { Peclet number: Pe }\end{array}$ \\
\hline Plug flow reactor with axial dispersion & $\begin{array}{l}\text { Mean residence time: } \tau \\
\text { half closed to the diffusion }\end{array}$ \\
\hline Plug flow reactor with axial dispersion & $\begin{array}{l}\text { Mean residence time: } \tau \\
\text { open to the diffusion }\end{array}$ \\
\hline
\end{tabular}

The use of well-known elementary "bricks" permits us to work directly in the Laplace domain where we know that the convolution product is transformed into a simple product of the functions:

$$
\begin{gathered}
\mathrm{L}(\mathrm{g}(\mathrm{t}))=\mathrm{G}(\mathrm{s})=\int_{0}^{\infty} \mathrm{e}^{-s t} g(t) \mathrm{d} t \\
L\left(g_{1} * g_{2}\right)=L\left(g_{1}\right) \cdot L\left(g_{2}\right)=G_{1}(s) \cdot G_{2}(s)
\end{gathered}
$$

If $Q_{k i}$ is the flow rate in the branch from node $k$ to node $i$, and $C_{i}$ is the concentration in the branches which start from node $i$, then we obtain the mass balances of node $i$ as following (Fig. 2).

Writing these mass balances can be done in a form of a matrix equation we have to solve: $[\mathrm{G}] \cdot[\mathrm{C}]=[\mathrm{K}]$ where:

[G] is the matrix complex of the transfer of a size equal to the number of the nodes;

[C] is the matrix column of the concentrations found by the nodes;

$[\mathrm{K}]$ is the matrix column constant that characterises the impulse of the incoming flow made by the injection node chosen.

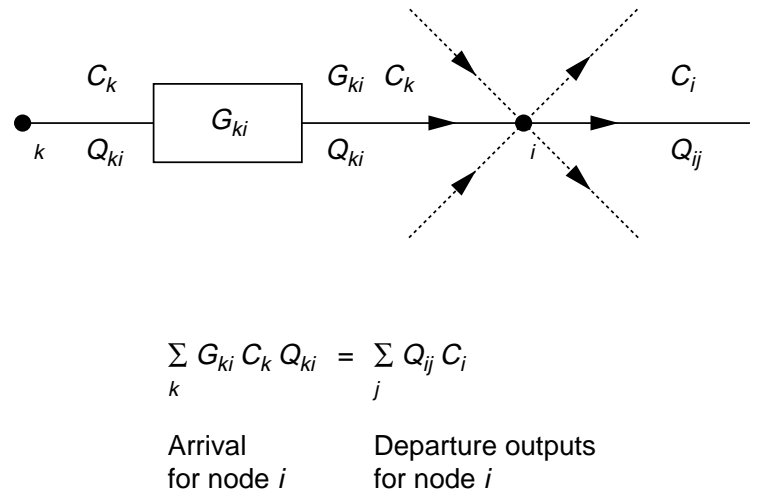

Figure 2

Principle scheme of mass balance at each node.

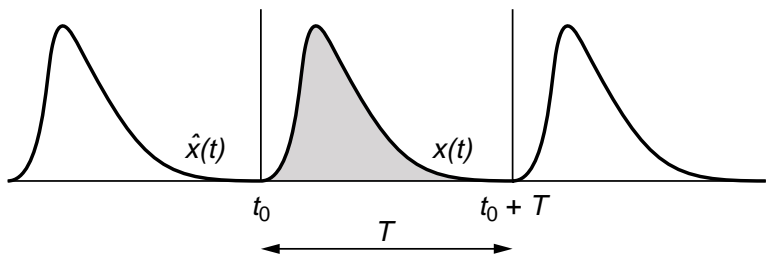

Figure 3

Principe of transformation of RTD signal into a periodic signal.

Transformation into real space is performed numerically by the Fast Fourier Transform (FFT) in order to determine the time-dependant concentration of the tracer on exit at the outlet of the system. It should be noted that the construction of the matrix, as well as the resolution of the associated equations (which necessitates an inversion of the matrix [G]), are totally transparent to the software user. The use of FFT involves generally to run the simulation with $2^{n}$ points (Leclerc et al., 1995). In order to avoid this limitation a new algorithm has been included in the version of the software presented in this paper. The procedure is represented in the following, illustrated by use of Figure 3.

A periodic signal $\hat{x}(t)$ can be obtained by periodical repetition of:

- $\hat{x}(t)=x(t)$ with $t_{0}<t<t_{0}+T$;

$-\hat{x}(t)=$ periodical of period $T$.

The signal $\hat{x}(t)$ has a Fourier transform $X(v)$ as follows:

$$
X(v)=\sum_{n=-\infty}^{+\infty} C_{n} \cdot \delta\left(v-n_{0}\right)
$$


with:

$$
\begin{gathered}
v_{0}=\frac{1}{T} \\
C_{n}=\frac{1}{T} \cdot \int_{t_{0}}^{t_{0}+T} \hat{x}(t) \cdot \mathrm{e}^{-2 \pi j \nu_{0} t} \mathrm{~d} t \\
C_{n}=\frac{1}{T} \sum_{k=0}^{N-1} \int_{\frac{k T}{N}}^{\frac{(k+1) T}{N}} \hat{x}(t) \cdot \mathrm{e}^{-2 \pi j n v_{0} t} \mathrm{~d} t
\end{gathered}
$$$$
\text { and: } \quad C_{n}=\frac{1}{T} \cdot \int_{t_{0}}^{t_{0}+T} \hat{x}(t) \cdot \mathrm{e}^{-2 \pi \mathrm{j}_{0} t} \mathrm{~d} t
$$

where $N$ is the number of intervals used for the calculation of the integral.

If $\frac{T}{N}$ is small by comparison with $T$ :

$$
C_{n}=\frac{1}{T} \sum_{k=0}^{N-1} \frac{T}{N} \cdot x\left(\frac{k t}{N}\right) \cdot \mathrm{e}^{-2 \pi j n \frac{k}{N}}
$$

or:

$$
\begin{gathered}
C_{n}=\frac{1}{N} \sum_{k=0}^{N-1} x\left(\frac{k t}{N}\right) \cdot \mathrm{e}^{-2 \pi j n \frac{k}{N}} \\
N C_{n}=N C_{n}^{*}=\frac{1}{N} \sum_{k=0}^{N-1} x\left(\frac{k t}{N}\right) \cdot \mathrm{e}^{2 \pi j n \frac{k}{N}}
\end{gathered}
$$

With:

$$
\begin{gathered}
x\left(\frac{k T}{N}\right)=X_{k}\left(\text { value of } x(t) \text { at the time } \frac{k T}{N}\right) \\
N C_{n}^{*}=\sum_{k=0}^{N-1} X_{k} \cdot \mathrm{e}^{2 \pi j n \frac{k}{N}}
\end{gathered}
$$

If $d$ is a divisor of $N$, then:

$$
\begin{aligned}
N C_{n}^{*}= & \sum_{k=0}^{\frac{N}{d}-1} X_{k} \cdot \mathrm{e}^{2 \pi j n \frac{k}{N}}+\sum_{k=\frac{N}{d}} X_{k} \cdot \mathrm{e}^{2 \pi j n \frac{k}{N}} \\
& +\ldots+\sum_{k=\frac{(d-1) N}{d}}^{N-1} X_{k} \cdot \mathrm{e}^{2 \pi j n \frac{k}{N}} \\
= & \sum_{k=0}^{\frac{N}{d}-1} X_{k} \cdot \mathrm{e}^{2 \pi j n \frac{k}{N}}+\sum_{k=0}^{\frac{N}{d}-1} X_{k+\frac{N}{d}} \cdot \mathrm{e}^{2 \pi j n \frac{k+\frac{N}{d}}{N}} \\
& +\ldots+\sum_{k=0}^{\frac{N}{d}-1} X_{k+\frac{(d-1) N}{d}} \cdot \mathrm{e}^{2 \pi j n \frac{k+\frac{(d-1) N}{d}}{N}} \\
= & \sum_{k=0}^{\frac{N}{d}-1}\left(X_{k}+X_{k+\frac{N}{d}} \cdot \mathrm{e}^{\frac{2 \pi}{d} j n}\right. \\
& \left.+\ldots+X_{k+\frac{(d-1) N}{d}} \cdot \mathrm{e}^{\frac{2 \pi(d-1)}{d} j n}\right) \cdot \mathrm{e}^{2 \pi j n \frac{k}{N}} \\
= & \sum_{k=0}^{\frac{N}{d}-1} X_{k}^{1, d} \cdot \mathrm{e}^{2 \pi j n \frac{k}{N}}
\end{aligned}
$$

with:

$$
\begin{aligned}
X_{k}^{1, d} & =\left(X_{k}+X_{k+\frac{N}{d}} \cdot \mathrm{e}^{\frac{2 \pi}{d} j n}+\ldots+X_{k+\frac{(d-1) N}{d}} \cdot \mathrm{e}^{\frac{2 \pi(d-1)}{d} j n}\right) \\
& =\sum_{p=0}^{d-1} X_{k} \cdot \mathrm{e}^{\frac{2 \pi p}{d} j n}
\end{aligned}
$$

If $\mathrm{d}^{m}$ is a divisor of $N$ :

$$
N C_{n}^{*}=\sum_{k=0}^{\frac{N}{d^{m}}-1} X_{k}^{m} \cdot \mathrm{e}^{2 \pi j n \frac{k}{N}}
$$

and:

$$
X_{k}^{i}=\sum_{k=0}^{d-1} X_{k}^{i-1, d} \cdot \mathrm{e}^{\frac{2 \pi p}{d^{i-1} j n}}
$$

this idea can be extended to all the first factors of $N$.

If $d_{1}, d_{2}, \ldots, d_{f}$ are the dividers of $N$ :

$$
N=\prod_{i=1}^{m} d_{i}
$$

with:

$$
N_{i}=\prod_{p=1}^{l} d_{i}
$$

We have thus:

$$
N C_{n}^{*}=X_{0}^{m}=\sum_{k=0}^{\frac{N}{N_{i}}-1} X_{k}^{i} \cdot \mathrm{e}^{2 \pi j n \frac{k}{N}}
$$

and:

$$
X_{k}^{i}=\sum_{k=0}^{d_{i}-1} X_{k}^{i-1} \cdot \mathrm{e}^{\frac{2 \pi p}{N_{i-1}} j n}
$$

The use of the methodology presented allows to run the simulation whatever the number of data.

\section{OPTIMISATION OF THE FLOW RATES}

Many complex industrial processes (mineral industries for example) involve undetermined flow rates of recirculation (Fig. 4). In such situation, the use of different probes at the outlet of each unit allows to determine the associated model by fitting the experimental curve (probe) with the theoretical response of the proposed model (node of visualisation). The optimisation of the parameters, which are only depending on the elementary reactors (Table 1) can be run easily (Leclerc et al., 1995). The optimisation of the flow rates of recirculation is much more difficult for three reasons:

- first, when one flow rate is modified, the other ones should change also in order to respect the mass balance;

- second, when one flow rate is modified, the corresponding "mean residence time" changes too;

- third, the software should determine by itself which flow rate should be estimated to calculate the mass balance at each node. 

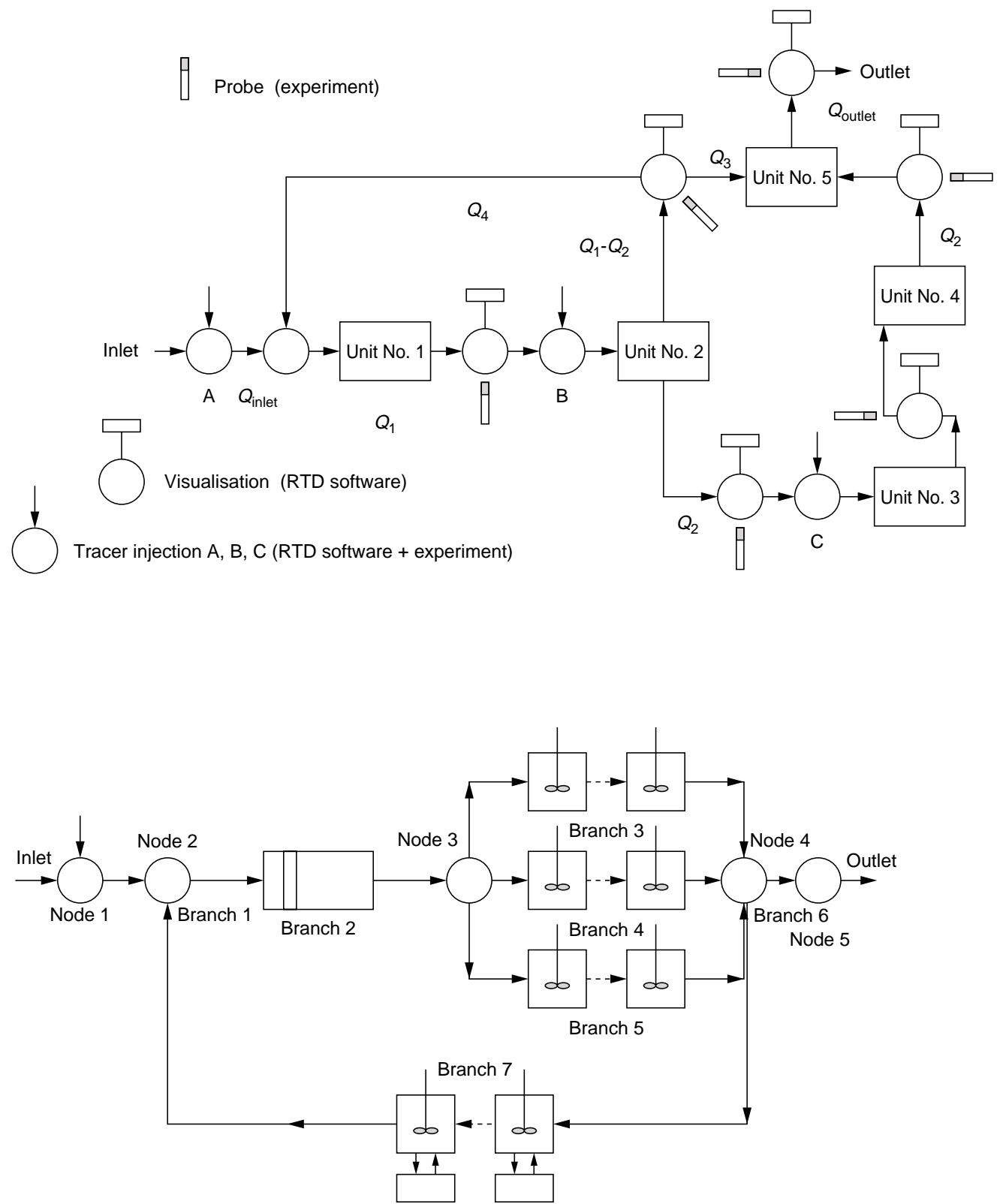

Figure 4

Typical complex process with recirculation between the different units.
Figure 5

Network example to explain the optimisation of flow rates.
A specific algorithm has been developed to solve this problem. Typical example of a possible structure (or model) is given in Figure 5. The algorithm first detects the fixed flow rates of the structure (inlet and outlet, flow rate fixed by the user, etc.). Then, since there are more non-fixed flow rates than mass balance equations, the algorithm determines itself the number of flow rates which should be optimised. The remaining ones will be determined through mass balance equations. Consequently, each branch has to be connected to at least one node for which all the other flow rates are determined. The "matrix of connection" (CONNEC) indicates the links between the different nodes and branches and the flow rate in these branches which can be optimised.
Consequently, the dimensions of the matrix of connection are given by the total number of nodes equal to the number of lines and the total number of branches equal to the number of columns. When the flow rate of the branch number $J$ can be optimised and when this branch is connected to the node number $I$, so $\operatorname{CONNEC}(I, J)=J$ elsewhere $\operatorname{CONNEC}(I, J)=0$.

To each set, one assigns its proper matrix. Values of each set are withdrawn from their matrix. If on a line of a matrix, which corresponds to a node, there is one non-null value, which corresponds to an unknown flow rate, it means that this flow rate can be estimated through mass balance, etc. At the end, if a matrix is null, then the corresponding set allows us to determine all the flow rates of the network. Once all the 
TABLE 2

Evolution of the matrix of connection during the calculation

$\begin{array}{lllllllll}\begin{array}{l}2 \mathrm{a} \\ \text { Branch }\end{array} & \mathbf{1} & \mathbf{2} & \mathbf{3} & \mathbf{4} & \mathbf{5} & \mathbf{6} & \mathbf{7} \\ \text { Node } & & & & & & & & \\ \mathbf{1} & 0 & 0 & 0 & 0 & 0 & 0 & 0 \\ \mathbf{2} & 0 & 2 & 0 & 0 & 0 & 0 & 7 \\ \mathbf{3} & 0 & 2 & 3 & 4 & 5 & 0 & 0 \\ \mathbf{4} & 0 & 0 & 3 & 4 & 5 & 0 & 7 \\ \mathbf{5} & 0 & 0 & 0 & 0 & 0 & 0 & 0 \\ & & & & & & & & \\ \text { dr } & & & & & & & & \\ \text { Branch } & \mathbf{1} & \mathbf{2} & \mathbf{3} & \mathbf{4} & \mathbf{5} & \mathbf{6} & \mathbf{7} \\ \text { Node } & & & & & & & \\ \mathbf{1} & 0 & 0 & 0 & 0 & 0 & 0 & 0 \\ \mathbf{2} & 0 & 2 & 0 & 0 & 0 & 0 & 7 \\ \mathbf{3} & 0 & 2 & 3 & 4 & 5 & 0 & 0 \\ \mathbf{4} & 0 & 0 & 3 & 4 & 5 & 0 & 7 \\ \mathbf{5} & 0 & 0 & 0 & 0 & 0 & 0 & 0\end{array}$

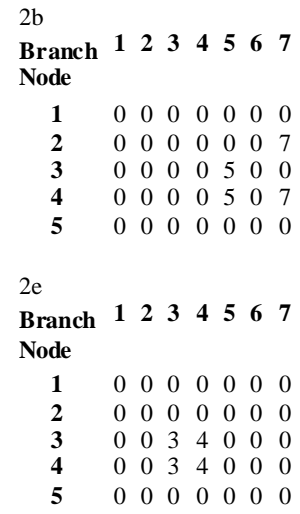

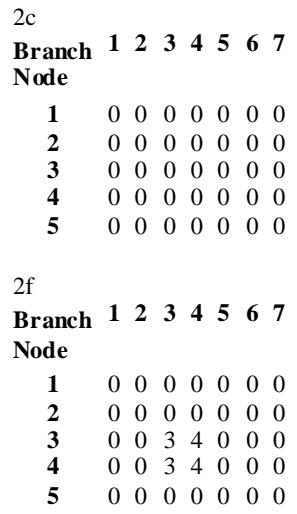

possible sets are obtained, the optimisation using the method of box complex can be run for each set. The solutions without any physical meaning are removed by the operator. The solution is considered to be the set with the lowest objective function, which is physically meaningful.

A simple example (Fig. 5) has been chosen to demonstrate the methodology. In the present case, the flow rates in the five branches (2, 3, 4, 5 and 7) are not fixed $a$ priori. The program allows us to determine that three flow rates are sufficient to describe the system. The matrix CONNEC has 5 lines and 7 columns as shown in Tables $2 \mathrm{a}$ and $2 \mathrm{~d}$. If the set chosen is $(2,3,4)$, matrix CONNEC is transformed as shown in Table 2b. For the set $(2,5,7)$, CONNEC is changed as shown in Table 2e. After calculation on lines, CONNEC on Table 2c is null while that on Table $2 \mathrm{f}$ is not, therefore the set $(2,3,4)$ is one of the solutions required whereas the $(2,5,7)$ is not. Solutions required are the seven following sets: $(2,3,4)$, $(2,4,5),(2,3,5),(3,4,5),(4,5,7),(3,4,7)$ and $(3,5,7)$.

The outlet of the model with different fixed flow rates has been simulated using the RTD software (Leclerc et al., 1995). Using the obtained result as a possible experimental curve, the new algorithm has been used to recover the possible sets to be optimised and to obtain the flow rates with a good accuracy. The same procedure has been successfully tested for complex networks involving a high number of branches and complex internal recirculation.

\section{AUTOMATIC GENERATION OF COMPARTMENT MODEL}

The existing software performs the estimation of parameters for fixed model structures provided by the user. The next step is to perform the generation of the model structures. This concept has been first published by Laquerbe et al. (1998). However, the used methodology is debatable. First, the model takes into account only two elementary reactors (plug flow reactor and perfect mixing cell). In addition, the example describing the methodology used is very atypical and the observation of the RTD curve allows to determine the structure of the model by optimisation. This case is not representative of typical curves, which can be described by different models. Moreover, the concept is based on a mathematical approach, which is not consistent with the main problem of the methodology. Indeed, a mathematical approach will choose the best transfer function based only on mathematical considerations, which may have no physical meaning. Physical aspects bring a knowledge of the system, which the mathematical aspect cannot bring from its nature.

As a consequence, automatic generation of RTD models needs both physical information about the process studied and a fitting procedure. Complex geometry induces a more complex flow behaviour and requires an adapted corresponding model. Although a simple model may be sufficient for representing correctly the RTD, it is not complete enough to describe the real flow and bring physical information on this flow.

A very good knowledge of the geometry of the reactor and operating conditions is thus necessary in order to establish a model as faithful as possible to the real flow, and permitting to draw some useful information for future experiments (better operating conditions, realistic simulations, etc.). Research is in progress to develop an expert system for the automatic generation of complex compartment models. The methodology is first based on the compilation of three series of existing results:

- relationships between physical characteristics of the studied process and the structure of the model (Table 3);

- relationships between process and existing model describing these processes (Table 4);

- relationships between characteristics of the tracer curves and structure of the model (surface of the tail, moments, etc.). 
TABLE 3

Typical examples of relationships between the model's characteristics and the characteristics of the studied process

\begin{tabular}{l|l}
\hline \multicolumn{1}{c|}{$\begin{array}{c}\text { Physical characteristics } \\
\text { of the studied process }\end{array}$} & \multicolumn{1}{c}{$\begin{array}{c}\text { Consequence } \\
\text { on the model }\end{array}$} \\
\hline $\begin{array}{l}\text { Multiple-agitator system } \\
\text { (Krystal-Olso crystalliser) }\end{array}$ & $\begin{array}{l}\text { Mixing cells in series with } \\
\text { backmixing }\end{array}$ \\
\hline $\begin{array}{l}\text { Multiple inlet } \\
\text { (chlorination process for water) }\end{array}$ & Model with several branches \\
\hline $\begin{array}{l}\text { Inlet at the upper position } \\
\text { of non-mixing system } \\
\text { (settling tank in waste water } \\
\text { treatment plant) }\end{array}$ & $\begin{array}{l}\text { Perfect mixing cells in series } \\
\text { exchanging with a dead volume }\end{array}$ \\
\hline & $\begin{array}{l}\text { Model with a branch of } \\
\text { recirculation (which is not } \\
\text { obvious through simple signal } \\
\text { for high flow of recirculation) }\end{array}$ \\
\hline
\end{tabular}

The compilation of a large number of such information will allow the software to eliminate some models which are not credible but also to help to describe partially the structure. The final choice can be determined with the help of a sophisticated algorithm (genetic algorithm for example).

\section{RTD MEASUREMENT UN DER UN STEADY-STATE CONDITION S}

The Residence-Time Distribution for steady-state conditions can be directly derived from a pulse injection of tracer in the studied process. However, for many industrial processes, the inlet flow $Q_{E}(t)$ and the outlet flow $Q_{S}(t)$ are time dependent.
This is especially the case for waste water treatment plants for which the inlet flow rate may change from 1 to 3 during the day and from 1 to 7 for a longer period depending on the climate. Experiments have been conducted in the pilot of an activated sludge channel reactor (Fig. 6). It is divided into several compartments by baffles. Its dimensions are $0.5 \mathrm{~m}$ long, $0.3 \mathrm{~m}$ large and $0.205 \mathrm{~m}$ high. Aeration is done uniformly, over the entire length, by tubes of stainless steel pierced with small holes. The experiments are undertaken with water and the tracer used is sodium chloride, detectable by conductimetry. Impulse injections of the salty solution are performed using a syringe. At steady state, the flow pattern can be modelled by perfect mixing cells in series: $N=4.6$ for $1 \mathrm{l} / \mathrm{min} ; N=3.9$ for $0.58 \mathrm{l} / \mathrm{min}$ and $N=7.5$ for $1.88 \mathrm{l} / \mathrm{min}$.

\section{TABLE 4}

Relationships between processes and existing models describing these processes

\begin{tabular}{l|l}
\hline \multicolumn{1}{c|}{$\begin{array}{c}\text { Studied processes } \\
\text { of the studied process }\end{array}$} & \multicolumn{1}{c}{\begin{tabular}{c}
\multicolumn{1}{c}{ Existing models } \\
in the literature
\end{tabular}} \\
\hline $\begin{array}{l}\text { Activated sludge channel } \\
\text { reactor }\end{array}$ & $\begin{array}{l}\text { Perfect mixing cells in series (the number } \\
\text { of the mixing cells is a function of both } \\
\text { gas and liquid flow rates) }\end{array}$ \\
\hline $\begin{array}{l}\text { Processes with endless } \\
\text { screws (extruders, mixers, } \\
\text { spiral classifiers, etc.) }\end{array}$ & $\begin{array}{l}\text { Perfect mixing cells in series exchanging } \\
\text { with a dead volume (the number of cells } \\
\text { is a function of both inlet flow rate } \\
\text { and speed of rotation) }\end{array}$ \\
\hline $\begin{array}{l}\text { Multiphase fixed-bed } \\
\text { reactors: RTD of liquid phase }\end{array}$ & $\begin{array}{l}\text { Two perfect mixing cells in series model } \\
\text { in parallel }\end{array}$ \\
\hline Classified bed crystallisers & $\begin{array}{l}\text { Perfect mixing cells in series } \\
\text { with backmixing }\end{array}$ \\
\hline
\end{tabular}

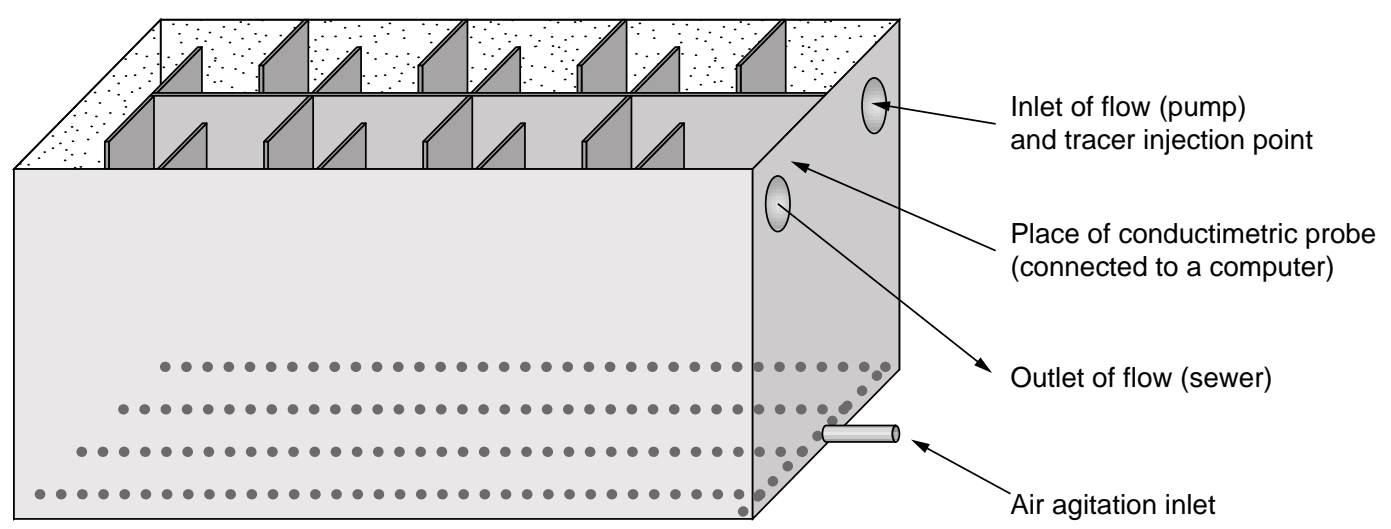

Figure 6

Pilot of the activated sludge channel reactor. 


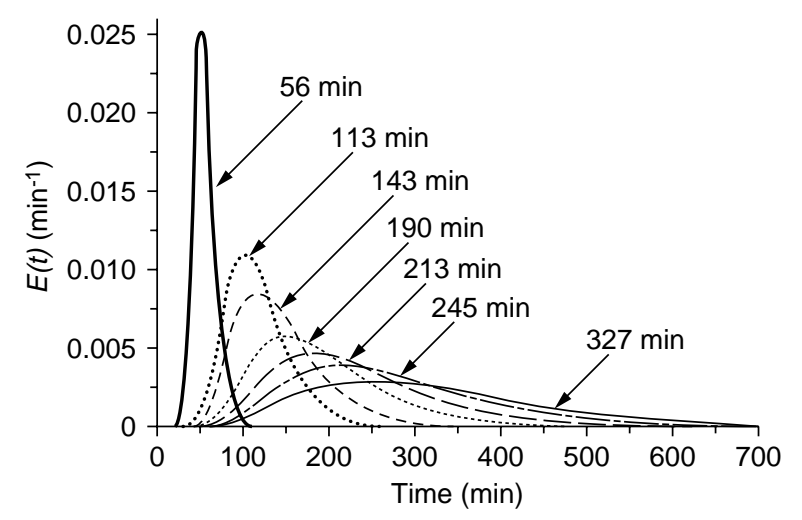

Figure 7

Influence of the mean residence time (i.e. inlet flow rate) on the Residence Time Distribution curve in an activated sludge channel reactor.

Figure 7 shows the strong effect of the inlet flow rate on the RTD curve and consequently on the associated compartment model (Potier et al., 1999).

Let $V(t)$ be the volume and $M$ the initial quantity of tracer injected in the reactor. The initial concentration of tracer is:

$$
C_{0}=\frac{M}{V(o)}
$$

and $C(t)$ is the concentration of tracer at current time $t$. Then, using mass balance, transfer functions could be easily found for different models and states (Table 5), with:

$$
\begin{gathered}
E_{\theta}=\frac{E(t) V}{Q_{S}}, \quad E_{\theta^{\prime}}=\frac{E(t) V}{Q_{S}(t)}, \quad E_{\theta^{\prime \prime}}=\frac{E(t) V(t)}{Q_{S}(t)} \\
\theta=\frac{t}{\tau}, \quad \theta^{\prime}=\frac{1}{V} \int_{0}^{t} Q_{S}(t) \mathrm{d} t \quad \text { and } \quad \theta^{\prime \prime}=\int_{0}^{t} \frac{Q_{S}(t)}{V(t)} \mathrm{d} t
\end{gathered}
$$

Niemi Antti et al. (1998) carried out experiments with a continuous flow vessel with mechanical agitator. They used chemical and radioisotope tracers for variations (sinusoidal) of flow rate $(0.450$ to $0.980 \mathrm{l} / \mathrm{min})$ and volume $(0.800$ to 1.200 1). Their results for unsteady-state conditions were close to those carried out in steady state. Fernandez-Sempere, Font-Montesinos and Espejo-Alcaraz (1995) investigated experiments with the waste water of their university, which is discharged in sewage system of Alicante (Spain). Flow rate (outlet flow around $10^{3} \mathrm{~m}^{3} / \mathrm{s}$ ) and volume variations are not periodic. Results are shown either in steady state or transient state but not together in order to see if a general RTD theory, derived from regular RTD for stationary conditions, is confirmed by experiments.

In the present work, the liquid volume was kept constant during the test. Figures 8 and 9 represent RTD curves in the activated sludge channel reactor at a mean flow rate $Q_{\text {mean }}=$ $1 \mathrm{l} / \mathrm{min}$. Figure 8 shows results for steady state at flow rate $Q=1 \mathrm{l} / \mathrm{min}$ and for transient state with a change of flow rate every 10 min period between two values of the amplitudes: $\pm 25 \%$ around the mean flow rate $Q_{\text {mean }}$ (dotted line) and $\pm 95 \%$ around the mean flow rate $Q_{\text {mean }}$ (thin solid line). In these operating conditions, the period of fluctuation is lower than the mean residence time. Figure 9 shows RTD curves for the same parameters but with a change of flow rate at a period of $20 \mathrm{~min}$. In this case, the period of fluctuation is higher than the mean residence time. Using the transfer function defined in Table 1 and the number of cells corresponding to the average flow rate $(N=4.6)$, the obtained RTD curves are similar in transient and steady states, despite an important influence of the flow rate on the number of cells. The observed fluctuations are mainly due to the difficulty to estimate accurately the flow rate. The typical inlet flow rate used during the experiment is shown on Figure 10. The measured signal is slightly different from the expected one. It is difficult to determine whereas this difference is due to the real fluctuations of flow rate or due to the measurement itself. This can partially explain differences in the experimental results. Other experiments have been performed in a fixed-bed column (Leclerc et al., 2000a) with similar conclusions. The use of this concept to predict performance of the reactor is still debatable. Further research including more complex flow rate fluctuations, compartment model with the split of internal flow rates and effect on both linear and strongly non-linear kinetics should be investigated.

\begin{tabular}{|c|c|c|c|}
\hline Model & Transfer function at steady state & $\begin{array}{c}\text { Transfer function with flow rate } \\
\text { variation }\end{array}$ & $\begin{array}{c}\text { Transfer function with flow rate } \\
\text { and volume variation }\end{array}$ \\
\hline Perfect mixing cell & $E_{\theta}=\exp (-\theta)$ & $E_{\theta^{\prime}}=\exp \left(-\theta^{\prime}\right)$ & $E_{\theta},=\exp \left(-\theta^{\prime \prime}\right)$ \\
\hline Perfect mixing cells in series & $E_{\theta}=\frac{N(N \theta)^{N-1}}{(N-1) !} \exp (-N \theta)$ & $E_{\theta^{\prime}}=\frac{N\left(N \theta^{\prime}\right)^{N-1}}{(N-1) !} \exp \left(-N \theta^{\prime}\right)$ & $\mathrm{E}_{\theta^{\prime \prime}}=\frac{N\left(N \theta^{\prime \prime}\right)^{N-1}}{(N-1) !} \exp \left(-N \theta^{\prime \prime}\right)$ \\
\hline Plug flow reactor & $E_{\theta}=\delta(1-\theta)$ & $E_{\theta},=\delta\left(1-\theta^{\prime}\right)$ & $E_{\theta,}=\delta\left(1-\theta^{\prime \prime}\right)$ \\
\hline
\end{tabular}

TABLE 5

Transfer functions in steady and transient states for different elementary reactors 


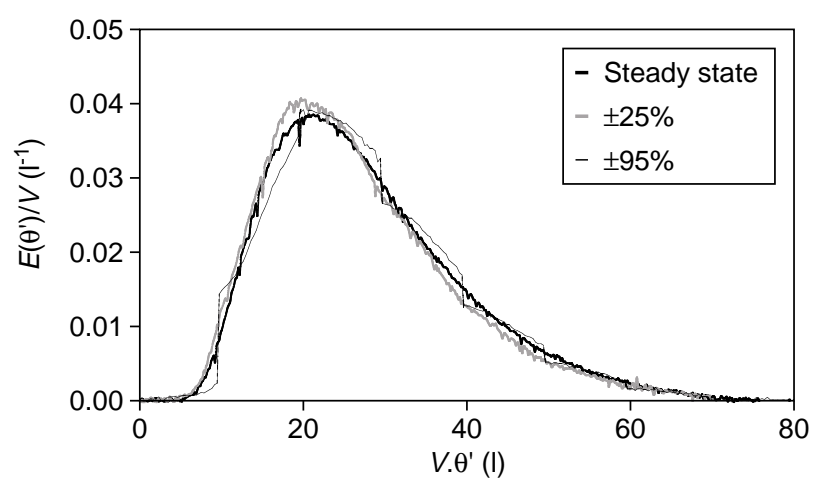

Figure 8

RTD under transient and steady states in the activated sludge channel reactor. The period of fluctuation $(10 \mathrm{~min})$ is lower than the mean residence time.

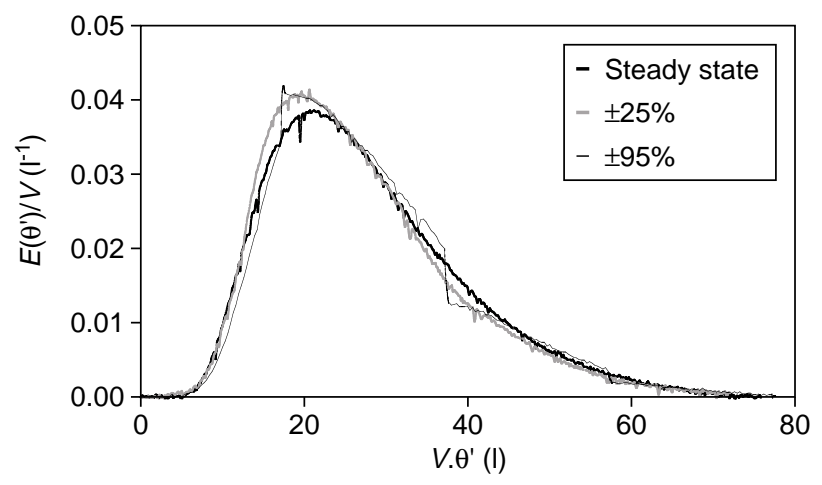

Figure 9

RTD under transient and steady states in the activated sludge channel reactor. The period of fluctuation $(20 \mathrm{~min})$ is higher than the mean residence time.

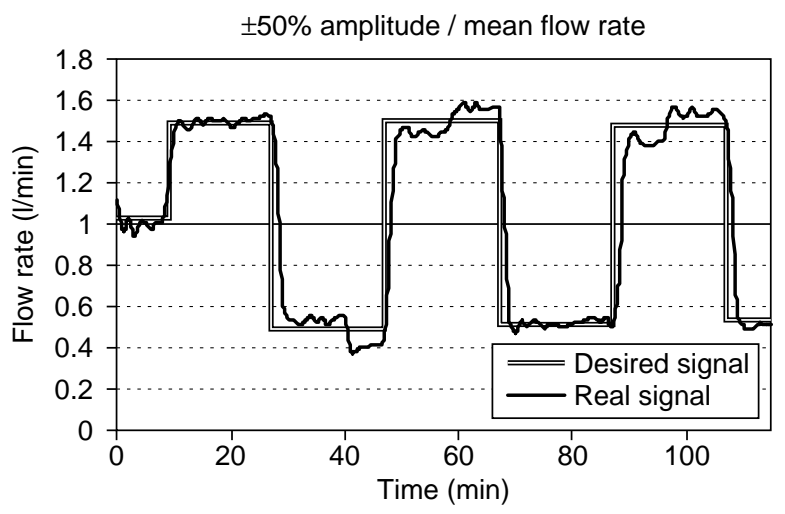

Figure 10

Typical inlet flow rate used during the experiments under transient-state conditions.

\section{CONCLUSIONS AN D PERSPECTIVES}

Up to now, the determination of hydrodynamic behaviour is mainly limited to two extreme approaches. The first one is the RTD interpretation through simple models, which gives general parameters such as the number of mixing cells. The second one is the use of Computer Fluid Dynamics, which provides an accurate description of the flow pattern. The first method is sometimes not sufficient whereas the second one is time-consuming and sometimes limited due to the complexity of the studied process. The extension of the first method through the creation of complex networks of elementary reactors and its use under transient state can overcome this problem. A software has been previously developed to make easier the creation of complex hydrodynamic models by interconnection of elementary reactors. All the parameters of the structure can be optimised through comparison with experimental tracer experiments. New developments allow us to determine the optimum flow rate distribution in complex hydrodynamic models. The creation of an expert system for deriving directly the structure of the model from experimental data and user experience is under development.

The theory of RTD under transient state has been experimentally confirmed for different operating conditions. The results show that even if the model is strongly dependent on the flow rate, the theory of RTD under transient state can be applied using the model of the average flow rate at steady state. Further studies will be conducted to determine the limits of use of this concept for more complex internal flow structures. Random flow rate fluctuations will be also tested to simulate more reliable industrial situations. If just a hydrodynamic model is needed to only understand the hydrodynamic behaviour of the studied process, this concept is useful. However, it is still not clear whereas the apparent good representation of the RTD curves allows to predict correctly the conversion. Experiments and simulations should be performed in presence of chemical reactions with strongly non-linear kinetics to determine the possible use of this concept.

Finally, new fields of research based on the RTD concept can be developed. The concept of RTD measurement in a microreactor is not clear. From the experimental point of view, it seems to be difficult to inject tracer without interference with the flow behaviour. From the theoretical point of view, the concept of perfect mixing cells is still debatable at the scale of local turbulence (Treguer, Leclerc and Lede, 1991).

For the processes involving gas-solid reaction, the respective RTDs of the two phases are not enough to predict the performance of the reactor. In this case, the reactions are depending on the contact time between gas and solid phase. It is necessary to estimate experimentally the so-called Contact Time Distribution (CTD) (Villermaux, 1995; Leclerc 
et al., 2000b). This concept has also been used to study the pollutant transfer in soil. However, all these studies are devoted to the limited case of a fixed solid phase. For pneumatic transport reactors for which the solid is also mobile and gas-solid reactions are strongly influenced by the flow behaviour of the two phases, it is necessary to estimate the CTD to predict the performance of the reactor. Few experiments and interpretation aiming at deriving CTD have been described in the literature. This concept should be in fact extended to the notion of Characteristic Time Distributions which takes into account the reactive phases involved in the studied processes. It is a general extension of the RTD concept.

The theory of RTD measurement for non-boundary systems needs to be elucidated. As an example, tracer experiments in oil fields for which small amounts of injected tracer are detected at the outlets need a more sophisticated theory to allow proper interpretation of the data.

\section{ACKN O W LEDG EMEN TS}

The authors are grateful to the workshop team of the LSGC who built the experimental set-up and they are indebted to Virginie Loiseau for her assistance in some experiments.

\section{REFEREN CES}

Blet, V., Berne, Ph., Chaussy, F., Tola, F. and Vitart, X. (1998) Récents développements en méthodologie du traçage radioactif. Récents Progrès en génie des procédés-Traceurs et méthodes de traçage, 12, 61, 9-15.

Calu, M.P. and Lameloise, M.L. (1986) Interprétation de mesures de dispersion de temps de séjour dans des écoulements de masse volumique variable. Application à la modélisation d'évaporateurs à flot montant de sucrerie. Entropie, 128, 13-22.

Danckwerts, P.V. (1953) Continuous Flow Systems, Distribution of Residence Times. Chemical Engineering Science, 2, 1, 1-13.

Fernandez-Sempere, J. (1997) Authors' Reply to the Comments of Ylemin R. and Niemi Antti A.J. Chemical Engineering Science, 52, 6, 1069-1071.

Fernandez-Sempere, J., Font-Montesinos, R. and Espejo-Alcaraz, O. (1995) Residence-Time Distribution for Unsteady-state Systems. Chemical Engineering Science, 50, 2, 223-230.

International Atomic Energy Agency (1996) Residence-Time Distribution Software Analysis. Computer Manual Series IAEA, 11.

Laquerbe, C., Laborde, J.C., Floquet, P., Pibouleau, L. and Domenech, S. (1998) Identification of Parametric Models Based on RTD Theory. Application to Safety Studies in Ventilated Nuclear Enclosures. Computers Chemical Engineering, 22, 3, 347-353.

Leclerc, J.P., Claudel, S., Lintz, H.G. and Antoine, B. (2000a) Recent Extensions of the Residence-Time Distribution Concept:
Unsteady State Conditions and Hydrodynamic Model Developments. Brazilian Journal of Chemical Engineering (submitted).

Leclerc, J.P., Detrez, C., Bernard, A. and Schweich, D. (1995) DTS : Logiciel d'aide à l'élaboration de modèles d'écoulement dans les réacteurs. Revue de linstitut français du pétrole, 50, 5, 641-656.

Leclerc, J.P., Gauthier, T., Houzelot, J.L. and Tereska, J. (2000b) Residence Time Methodology as Applied to Industrial Processes: an Obsolete Concept or an Underemployed Tool? Brazilian Journal of Chemical Engineering (submitted).

Leclerc, J.P., Muhr, H., Findeling, C., Terriere, J. and Charonnat, Y. (1996) Modélisation de l'écoulement de l'eau et du filler dans un malaxeur industriel et détermination de son pouvoir de lissage. Bulletin de liaison des laboratoires des Ponts et Chaussées, 201, 5-15.

Levenspiel, O. (1999) Chemical Reaction Engineering, 3rd ed., John Wiley \& Sons.

Lin, W., Weinell, C.E., Hansen, P.F.B. and Dam-Johansen, K. (1999) Hydrodynamics of Commercial Scale CFB Boiler-Study with Radioactive Tracer Particles. Chemical Engineering Science, 54, 22, 5495-5506.

Matko, T., Fawcett, N., Sharp, A. and Stephenson, T. (1996) A Numerical Model of Flow in Circular Sedimentation Tanks. Institution of Chemical Engineers, 74, Part B, 197-204.

Muhr, H., Leclerc, J.P., David, R. (1999) Fluorescent UV Dye: a Particularly Well-Suited Tracer to Determine Residence-Time Distributions of Liquid Phase in Large Industrial Reactors. Analusis, 27, 6, 541-543.

Nauman, E.B. (1969) Residence-Time Distribution Theory for Unsteady Stirred Tank Reactors. Chemical Engineering Science, 24, 9, 1461-1470.

Niemi Antti, J. (1977) Residence-Time Distributions of Variable Flow Processes. International Journal of Applied Radiation and Isotopes, 28, 855-860.

Niemi Antti, J. (1997) Some Comments on "Residence-Time Distribution for Unsteady-State Systems" by Fernandez-Sempere J. Chemical Engineering Science, 52, 6, 1065-1067.

Niemi Antti, J., Zenger, K., Tereska, J. and Martinez, J.G. (1998) Tracer Testing of Processes under Variable Flow and Volume. Nukleonika, 43, 1, 73-94.

Potier, O., Pons, M.N., Roche, N., Leclerc, J.P. and Prost, C. (1999) Hydrodynamics of Activated Sludge Channel Reactor. Conference Proceedings Hungarian Journal of Industrial Chemistry, 28, 1, 49-51.

Treguer, V., Leclerc, J.P. and Lede, J. (1991) Problématique de la détermination expérimentale de l'hydrodynamique dans les micro-réacteurs : Limites d'utilisation de la méthode des distributions de temps de séjours. Récents Progrès en génie des procédés, 5, 14, 493-498.

Van Hasselt, B., Calis, H.P.A., Sie, S.T. and van den Bleek, C.M. (1999) Gas- and Liquid-Phase Residence-Time Distribution in the Three-Levels-of-Porosity Reactor. Chemical Engineering Science, 54, 21, 5047-5053.

Villermaux, J. (1995) Génie de la réaction chimique, 2nd ed., Tec \& Doc-Lavoisier.

Final manuscript received in December 2000 